\title{
Multiple Research Methodologies Can Advance the Science of Family Medicine
}

\author{
Dean A. Seebusen, MD, MPH, Marjorie A. Bowman, MD, MPA, \\ and Anne Victoria Neale, $\mathrm{PhD}, \mathrm{MPH}$
}

This issue of the Journal evidences the wide variety of research methods that can effectively answer questions important to the practice of family medicine. For example, this issue includes 4 highly informative reports from qualitative or mix-methods research, plus surveys, a meta-analysis, a case report, and more. Mixed-methods were used to look at practice changes and to compare advance directive tools. Surveys were used to identify practical, but addressable, issues for mailed colon cancer screening tests, and the prevalence of atopic dermatitis, and emollient use in young children. Secondary analyses of national surveys were used to identify low-value patient requests, and how diabetes and prediabetes are being treated. Retrospective chart analysis of patients with frequent hospital admissions identified important characteristics of the patients and their problems. Meta-analysis methodology was used to stratify risks for pneumonia. And, a randomized trial was used to compare ways to train patients to use medical record patient portals. (J Am Board Fam Med 2019;32:123-125.)

Some research methods provide stronger evidence than others, and some are primarily exploratory or hypothesis generating. Generally, randomized controlled trials produce more reliable outcomes than retrospective chart reviews, but are more expensive, and sometimes cannot actually be undertaken or completed. In addition, various types of research questions require different methods. Sometimes a survey is the right choice to answer a given question. Qualitative methods, and mixed methods, often bring more nuanced answers that help explore the "why" behind the "what," which in turn can significantly assist implementation of needed practice changes. Case reports, even though sometimes maligned as a research method, can be highly informative and can lead to new discoveries. Therefore, $7 A B F M$ publishes articles that use a wide variety of research methods; the key is their clarity, the appropriateness of the method to the topic, and the importance to the practice of family medicine.

This issue of the fournal includes 4 reports from qualitative or mixed-methods research that highlight the value of these methods. For example, qualitative methods were used to evaluate the usability of a toolkit published by the Agency for

Conflict of interest: The authors are editors of the $7 A B F M$.
Health care Research and Quality, and designed to guide practices toward a standardized and efficient laboratory testing process. The findings underscore the role of a sound quality improvement infrastructure for practices to effectively implement such toolkits. ${ }^{1}$ Liddy et $\mathrm{al}^{2}$ used mixed methods to study implementation of electronic consultations in a health network in Ontario, Canada. Both quantitatively and qualitatively, the implementation was a success. Participants described increased trust and collegiality between primary care providers and specialists. Among the positive outcomes, perhaps most important was that over $40 \%$ of the patients were retained in primary care without the need for a face-to-face consultation in a specialist's office.

Kendall et $\mathrm{al}^{3}$ also used mixed methods to evaluate how clinics providing HIV care in Canada aligned with the patient-centered medical home (PCMH) model. They looked at both primary-care and specialty-care settings. Their findings highlight how important the tenets of the PCMH model are to providing excellent care to patients as well as how challenging implementation of some elements can be. Many of the barriers identified will be familiar to American family physicians. In more mixed-methods research, 2 advanced directive forms were compared in Oklahoma using retrospective chart reviews and semistructured inter- 
views with patients and health care providers. Having patients' end-of-life wishes clearly documented is an important but challenging goal for family physicians. Providing patients with a better tool to address these very personal questions can greatly increase the number of patients who begin the process. $^{4}$

Survey methodology is useful to investigate a wide range of interesting questions. Ylitalo et $\mathrm{al}^{5}$ explored rates of returned fecal immunochemical test (FIT) kits for colorectal cancer screening in a large federally-qualified health center. They surveyed those who did and those who did not return their FIT kits to identify barriers and facilitators to the process. The results point toward system-based improvements that can be implemented to increase cancer screening rates in underserved populations. Over the years, the benefits of acupuncture have been shown for a wide variety of clinical conditions. In an intriguing report of survey results, evidence is presented that acupuncture training may have beneficial effects for providers as well, possibly helping to mitigate physician depersonalization and physician burnout. ${ }^{6}$

The Meta-LARC Consortium ${ }^{7}$ used a cross-sectional survey to estimate the prevalence of atopic dermatitis among children under the age of 5 , and to examine the skin care habits within these households. The results reveal that the burden of atopic dermatitis is surprisingly high and that there is plenty of room for family education regarding this condition. In another manuscript, an exit survey of patients after appointments in an academic family medicine clinic confirms what we have all experienced-patient requests in primary-care visits are common. Fenton et $\mathrm{al}^{8}$ report patient characteristics associated with these requests, and suggest potentially valuable next steps to address low-value requests that may stimulate readers' thinking about what it means when patients do not have requests. This is a great example of "in-clinic research" that opens the door to many more possible research projects.

Secondary analysis of existing data, especially of large databases, is good way to address big questions about the way medicine is actually practiced on a daily basis. Shealy et $\mathrm{al}^{9}$ conducted secondary analysis of the National Ambulatory Medical Care Survey database to examine how often diabetes is screened for, as recommended by American Diabetes Association. Rates and types of treatment for prediabetes were also evaluated. In the context of rising numbers of patients with diabetes and prediabetes, the results are surprising and disappointing. In a fascinating secondary analysis of Medicare claims data, ${ }^{10}$ physician characteristics associated with low value care (LVC) -spending were identified. Given the relentless increase in health care costs, minimizing LVC is more important than ever. Which physicians would you think spend more on LVC? Men or women? New physicians or seasoned physicians? How do you think family physicians compare with other specialties?

Kirkpatrick et $\mathrm{al}^{11}$ used a retrospective analysis of electronic medical records to identify characteristics of patients who are highly utilizers of the emergency department. While high-using patients changed over time, demographic characteristics did not. The authors use these results to make recommendations regarding how limited system resources might best be focused to minimize future visits.

The use of a highly accurate point of care influenza test shows promising results in a quasi-experimental prospective trial conducted at a university student health clinic. $^{12}$ While follow-up studies with stronger methodologies and a cost-effectiveness analysis will be needed, this new-generation PCR-based influenza test could have significant impact on antibiotic use and return visits in patients presenting with flu-like illnesses.

Marchello et $\mathrm{al}^{13}$ provide us with a very useful meta-analysis that helps stratify the risk of community-acquired pneumonia in adult patients with acute respiratory infections. Case reports with a review of the literature can be a very effective way of filling in holes in the existing medical literature. Such a hole current exists regarding how to treat patients whose Nexplanon rods are found to be broken. A report of 2 such cases from the University of Arizona reviews the literature and offers clinical advice for other providers facing this dilemma. ${ }^{14}$

Two well-done studies in this issue show that direct comparison of existing options often provides enlightening results. Tong et $\mathrm{al}^{15}$ compare 2 tools that can be used to screen for prescription psychotherapeutic medication misuse. Such tools are clearly needed to help family physicians combat the ongoing wave of prescription medication misuse-opioids and otherwise. Patient portals can also be a valuable resource for facilitating commu- 
nication between patients and the health care system and patients' engagement in their care. Of course, portals do not help if patients cannot, or will not, use them. A team from University of California San Francisco ${ }^{16}$ randomized patients to 1 of 2 methods for training on their health system's patient portal. The successes, and failures, of both training methods highlight the ongoing need for improvements in patient portal features and usability.

The family medicine research agenda is incredibly broad, and needs many methodologies to move forward. We encourage readers to think about their own questions and consider which of these methods they can use to answer them. We look forward to seeing what you discover. In the meantime, please enjoy reading the wide range of methods reported in this issue of the fournal.

Please also see the annual "Thanks to Reviewers" note in this issue. Peer review is the life blood of science, and we greatly appreciate our reviewers' time, expertise and generosity as we build the evidence-base of primary care.

To see this article online, please go to: http://jabfm.org/content/ 32/2/123.full.

\section{References}

1. Kwan BM, Fernald D, Ferrarone P, et al. Implementation and evaluation of a laboratory safety process improvement toolkit. J Am Board Fam Med 2019; 32:136-45.

2. Liddy C, Moroz I, Mihan A, Keely E. Assessment of the generalizability of an eConsult service through implementation in a new health region. J Am Board Fam Med 2019;32:146-57.

3. Kendall CE, Shoemaker ES, Porter JE, et al. Canadian HIV care settings as patient-centered medical homes (PCMHs). J Am Board Fam Med 2019;32: $158-67$.

4. Wickersham E, Gowin M, Deen M, Nagykaldi Z. Improving the adoption of advance directives in primary care practices. J Am Board Fam Med 2019;32: 168-79.

5. Ylitalo KR, Camp BG, Umstattd Meyer MR, et al. Barriers and facilitators of colorectal cancer screen- ing in a federally-qualified health center (FQHC). J Am Board Fam Med 2019;32:180-90.

6. Crawford P, Rupert J, Jackson J, Walkowski S, Ledford CJW. Relationship of training in acupuncture to physician burnout. J Am Board Fam Med 2019; 32:259-63.

7. Al-naqeeb J, Danner S, Fagnan LJ, et al. The burden of childhood atopic dermatitis in the primary care setting: a report from the Meta-LARC Consortium. J Am Board Fam Med 2019;32:191-200.

8. Fenton JJ, Magnan EM, Jerant A, Kravitz RL, Franks P. Patient characteristics associated with making requests during primary care visits. J Am Board Fam Med 2019;32:201-208.

9. Shealy KM, Wu J, Waites J, Taylor NA, Sarbacker GB. Patterns of diabetes screening and prediabetes treatment during office visits in the US. J Am Board Fam Med 2019;32:209-17.

10. Barreto TW, Chung Y, Wingrove P, et al. Primary care physician characteristics associated with low value care spending. J Am Board Fam Med 2019; 32:218-25.

11. Kirkpatrick S, Agana DFG, Lynch K, Carek P. Emergency department high utilizers among family medicine patients. J Am Board Fam Med 2019;32: 264-68.

12. Dale AP, Ebell M, McKay B, Handel A, Forehand R, Dobbin K. Impact of a Rapid point of care test for influenza on guideline consistent care and antibiotic use. J Am Board Fam Med 2019;32:226-33.

13. Marchello CS, Ebell MH, Dale AP, Harvill ET, Shen Y, Whalen CC. Signs and symptoms that rule out community-acquired pneumonia in outpatient adults: a systematic review and meta-analysis. J Am Board Fam Med 2019;32:234-47.

14. Campodonico J, Wolfrey J, Buchanan J. Reports of two broken Nexplanon $®$ rods. J Am Board Fam Med 2019;32:269-71.

15. Tong ST, Polak KM, Weaver MF, Villalobos GC, Smith WR, Svikis DS. Screening for psychotherapeutic medication misuse in primary care patients: comparing two instruments. J Am Board Fam Med 2019;32:272-78.

16. Lyles C, Tieu L, Sarkar U, et al. A randomized trial to train vulnerable primary care patients to use a patient portal. J Am Board Fam Med 2019;32: 248-58. 